\title{
IncN plasmids mediate UV resistance and error- prone repair in Pseudomonas aeruginosa PAO
}

\author{
Tyler A. Kokjohn ${ }^{1}$ and Robert V. Miller ${ }^{2}$
}

Author for correspondence: Robert V. Miller. Tel: +1 4057447180 . Fax: +1 4057446790 .

1 School of Biological

Sciences, University of

Nebraska-Lincoln, Lincoln,

NE 68588-0118, USA

2 Department of

Microbiology and

Molecular Genetics,

Oklahoma State University,

Stillwater, OK 74078, USA

\begin{abstract}
While it seems likely that the ability to induce the expression of recAcontrolled genes is nearly universal among the eubacteria, the expression of plasmid-borne ultraviolet (UV)-resistance and mutagenesis genes seems to be species-dependent in a complex fashion. Some plasmids encoding UVresistance and mutagenesis functions only express these phenotypes in a select number of bacterial species. Several UV-resistance plasmids that express these functions in Escherichia coli are either unstable or simply do not express the UV-resistance-mutagenesis phenotype in Pseudomonas aeruginosa. In order to clarify the role of these plasmids in microbial ecology, we have undertaken a study of the ability of the well-characterized UV-resistance IncN plasmids PKM101 and R46 to express the UV-resistance phenotype in $P$. aeruginosa. In addition, we have examined the IncP plasmids RP4 and R68.45, observed to confer a UV-resistant phenotype upon Myxococcus xanthus, for the ability to express this phenotype in $P$. aeruginosa. Our experiments reveal that while pKM101 and R46 transfer to $P$. aeruginosa at a very low frequency, these plasmids, once transferred, are maintained and clearly support the expression of the UV-resistance and mutagenesis phenotype observed in $E$. coli. Studies of plasmids R68.45 and RP4 in P. aeruginosa revealed that they do not express UV-resistance functions in this species. UV-resistance plasmids may play an important role in the natural ecology of bacterial habitats exposed to solar radiation or to various DNA-damaging natural and man-made chemicals.
\end{abstract}

Keywords: Pseudomonas aeruginosa, UV-resistance plasmids, Weigle reactivation/mutagenesis, $\operatorname{rec} A, \mathrm{SOS}$ response

\section{INTRODUCTION}

A large number of bacterial plasmids have been determined to affect cell survival and mutagenic responses to ultraviolet (UV) irradiation. These plasmids frequently result in a UV-resistant $\left(U^{r}\right)$ phenotype. Plasmids producing such effects have been observed in a wide variety of bacterial genera (Pinney, 1980; Boronin, 1992).

Plasmid-encoded enhanced UV resistance may provide a selective advantage to the host in certain environments. Both enhanced mutagenesis and additional resistance to UV damage have the potential to impart additional fitness to the bacterium in selected habitats (Sedgwick \& Goodwin, 1985; Sedgwick et al., 1989). However, the frequency and dynamics of UV-resistance plasmids in natural ecosystems and the contribution of such plasmids to cell survival and evolution are unknown.

Molecular analyses of some of the plasmid genes responsible for the $\mathrm{UV}^{\mathrm{r}}$ phenotype has revealed their relationship to the $u m u D C$ operon of Escherichia coli (Walker, 1984; Strike \& Lodwick, 1987). The chromosomal $u m u D C$ genes are required for UV-induced mutagenesis in E. coli and are components of the SOS network. The muc $A B$ operon of pKM101 (Walker, 1984) and the impCAB genes of TP110 (Glazebrook et al., 1986) produce analogues of the $u m u D C$ operon that are clearly controlled by the host lex $A-\operatorname{rec} A$ regulatory system.

Many bacterial species have been shown to encode analogues of the $\operatorname{rec} A$ gene of E. coli (Miller \& Kokjohn, 1990). Some of these analogues are capable of inducing the SOS network of E. coli (Miller \& Kokjohn, 1990). Experimental evidence makes clear that the capacity to induce expression of analogues of muc $A B$ present on UVresistance plasmids will be widely distributed among the bacteria.

Both $\operatorname{rec} A$ (Miller \& Kokjohn, 1990) and lex $A$ (Calero et al., 1991; Garriga et al., 1992) structural analogues have been identified in several species of Pseudomonas including 
Table 1. Bacterial strains used in this study

$\left.\begin{array}{|ccc|}\hline \text { Bacterium } & \text { Relevant genotype } & \text { Reference } \\ \hline \begin{array}{c}\text { Escherichia coli } \\ \text { AB1157 }\end{array} & \begin{array}{c}\text { thi-1 thr-1 leuB6 proA2 } \\ \text { bis-4 argE3 }\end{array} & \begin{array}{c}\text { Clark \& Margulies } \\ (1965)\end{array} \\ \text { Psendomonas } & & \\ \begin{array}{c}\text { aeruginosa } \\ \text { PAO1 }\end{array} & \text { Prototrophic } \\ \text { PAO25 } & \text { argF10 leu-10 derivative } \\ \text { of PAO1 } & \text { Simonson et al. } \\ \text { PAO303 } & \text { argB21 derivative of } \\ & \text { PAO1 }\end{array}\right\}$

Pseudomonas aeruginosa. While $P$. aeruginosa has been shown to contain UV-inducible genes (Miller \& Kokjohn, 1988; Horn \& Ohman, 1988; Warner-Bartnicki \& Miller, 1992), several studies have suggested that the $P$. aeruginosa chromosome does not contain functional analogues to the umuDC operon (Benbrook \& Miller, 1986; McBeth, 1989; Simonson et al., 1990). The expression of plasmidborne UV-resistance and mutagenesis-promoting genes seems to be species-specific in a complex fashion (Jacoby, 1977; McCann \& Clarke, 1981; Tardif \& Grant, 1983; Hofemeister et al., 1979).

Moreover, other studies have revealed that these UVdamage-resistance genes may be present on certain broadhost-range plasmids that are expressed only in certain genetic backgrounds (Hofemeister et al., 1979). These studies have revealed that plasmids RP1 and R68.45 support UV-damage-induced repair and mutagenesis in Myxococcus sp. but not in a variety of other bacterial species. The molecular basis for the UV-resistance phenotype exhibited in Myxococcus sp. has not been studied.

Because of the apparent complexities of expression of plasmid-borne UV resistance genes in bacteria, we have undertaken a series of experiments to assess the potential of these plasmids to express the $\mathrm{UV}^{\mathrm{r}}$ phenotype in $P$. aeruginosa, a species in which repair and mutagenesis have been extensively characterized. Plasmids carrying muc $A B$ analogues of the $E$. coli $u m u D C$ operons known to be regulated by the $\operatorname{lex} A-\operatorname{rec} A$ network were included. These studies allowed a determination of the ability of UV exposure to regulate $m u c A B$ expression in $P$. aeruginosa.

\section{METHODS}

Bacteria, plasmids, and bacteriophages. The bacterial strains and plasmids used in this study are described in Tables 1 and 2. Bacteriophage D3 is a temperate, specialized transducing phage of $P$. aeruginosa PAO (Cavenagh \& Miller, 1986). A spontaneously occurring clear-plaque mutant of D3 used in our studies has been designated D3c. Phage lysates were prepared by the method of Miller \& Ku (1978).

Media. Luria broth (LB) consists of $1 \%(\mathrm{w} / \mathrm{v})$ tryptone, $1 \%$ (w/v) $\mathrm{NaCl}$ and $0.5 \%$ yeast extract. Luria agar (LA) is LB containing $1.3 \%(\mathrm{w} / \mathrm{v})$ agar. Lambda top agar is $1 \%$ tryptone, $0.5 \% \mathrm{NaCl}$ and $0.65 \%$ agar. Pseudomonas Isolation Agar was purchased from Difco. Saline for dilutions is $0.85 \% \mathrm{NaCl}$. TNM buffer is $10 \mathrm{mM}$ Tris/ $\mathrm{HCl}, \mathrm{pH} 7 \cdot 4,150 \mathrm{mM} \mathrm{NaCl}$ and $10 \mathrm{mM} \mathrm{MgSO}_{4}$. Antibiotics were obtained from Sigma and used at the following concentrations: rifampicin, $75 \mu \mathrm{g} \mathrm{ml}^{-\mathbf{1}}$; carbenicillin, $300 \mu \mathrm{g} \mathrm{m}^{-1}$ for $P$. aeruginosa; ampicillin, $50 \mu \mathrm{g}$ $\mathrm{ml}^{-1}$ for E. coli; tetracycline, $12.5 \mu \mathrm{g} \mathrm{ml}^{-1}$ for $E$. coli and $250 \mu \mathrm{g} \mathrm{ml}^{-1}$ for $P$. aeruginosa.

Plasmid conjugation procedure. Recipient cells ( $P$. aeruginosa) were grown at $37^{\circ} \mathrm{C}$ in LB to late exponential phase. Donors (E. coli) strains were grown at $37^{\circ} \mathrm{C}$ to mid-exponential phase in LB under antibiotic selection. The cells were harvested by centrifugation, suspended in an equal volume of $L B$ and mixed in a donor: recipient ratio of $1: 1$. The conjugation mixture was spread on an LA plate and incubated at room temperature for $24-48 \mathrm{~h}$. The cells were removed from the plate by washing with saline and the resulting suspension was plated on Pseudomonas Isolation Agar containing carbenicillin.

UV protection and chromosomal mutagenesis procedures. $P$. aeruginosa cells were grown at $37^{\circ} \mathrm{C}$ in LB. Medium for strains containing plasmids was supplemented with carbenicillin. Cells were harvested by centrifugation, and the pellet suspended in an equal volume of $0.85 \%$ saline. The saline-suspended cells were

Table 2. Plasmids used in this study

\begin{tabular}{|lcll|}
\hline Plasmid & $\begin{array}{c}\text { Incompatibility } \\
\text { group } \\
\text { E. colif } \\
\text { P. aeruginosa } \dagger\end{array}$ & Relevant phenotype $\ddagger$ & \multicolumn{1}{c|}{ Reference } \\
\hline RP4 & IncP/IncP-1 & $\mathrm{Ap}(\mathrm{Cb}) \mathrm{Tc} \mathrm{Km} \mathrm{UV*}$ & Jacoby (1978) \\
R68.45 & IncP/IncP-1 & $\mathrm{Ap}(\mathrm{Cb}) \mathrm{Tc} \mathrm{Km} \mathrm{UV*}$ & Haas \& Holloway (1978) \\
R2 & $\mathrm{NR} /$ IncP-9 & $\mathrm{Cb} \mathrm{Sm} \mathrm{Tc} \mathrm{Su} \mathrm{UV} \mathrm{in} \mathrm{P.}$ & Simonson et al. (1990) \\
R46 & Incruginosa $/$ ? & $\mathrm{Ap}(\mathrm{Cb}) \mathrm{Tc} \mathrm{Km} \mathrm{Su} \mathrm{Sm} \mathrm{UV}$ & Mortelmans \& Stocker (1976) \\
pKM101 & IncN/? & $\mathrm{Ap}(\mathrm{Cb}) \mathrm{Km} \mathrm{UV}$ & Walker (1977) \\
\hline
\end{tabular}

$\dagger$ NR, Does not replicate in E. coli; ?, IncP incompatibility group unknown, will replicate in $P$. aeruginosa.

$\ddagger \mathrm{Ap}(\mathrm{Cb})$, resistance to ampicillin in E. coli and carbenicillin in P. aeruginosa; $\mathrm{UV}^{*}$, resistance phenotype expressed in Myxococcus xantbus (McCann \& Clark, 1981). 
exposed to UV radiation from a GE germicidal lamp. Dose was determined with a UVX radiometer (Ultraviolet Products). Appropriate dilutions were made in $0.85 \%$ saline with $0.1 \mathrm{ml}$ samples plated on LA and incubated in the dark at $37^{\circ} \mathrm{C}$ to determine percentage survival. Precautions were taken to avoid photoreactivation.

The chromosomal mutation frequency was estimated by plating $0.1 \mathrm{ml}$ samples of irradiated cells on LA followed by overnight incubation at $37^{\circ} \mathrm{C}$. These plates were replica-plated onto LA containing rifampicin to determine the frequency of rifampicinresistant cells (Simonson et al., 1990).

Host cell reactivation (HCR) procedures. Lysates of phage D3c $\left(2 \times 10^{8}\right.$ p.f.u. $\left.\mathrm{ml}^{-1}\right)$ in TNM buffer were exposed to various doses of UV radiation and used to infect host cells in the early exponential phase of growth. Lambda top agar was added, and the mixture plated on LA containing appropriate antibiotics. Phage titres were determined after incubation at $37^{\circ} \mathrm{C}$ in the dark overnight.

Weigle reactivation and mutagenesis procedures. For Weigle reactivation experiments, lysates of phage D3c were irradiated with a dose of UV that resulted in approximately $0.01 \%$ plaque survival in unirradiated host bacteria. Irradiated phage lysates were diluted in TNM buffer. Bacteria were grown in LB to early exponential phase, harvested by centrifugation, suspended in an equal volume of $0.85 \%$ saline, and exposed to various doses of UV radiation. Samples $(0.1 \mathrm{ml})$ of irradiated bacteria were mixed with dilutions of unirradiated and irradiated phage lysates. Phage adsorption was allowed to occur at $37^{\circ} \mathrm{C}$ in the dark. Lambda top agar was added and the mixture poured onto LA plates containing appropriate antibiotics. The plates were incubated overnight at $37^{\circ} \mathrm{C}$ in the dark. The Weigle reactivation factor (WRF) was calculated from the formula

$\mathrm{WRF}=\frac{\left[(\text { p.f.u. })_{\mathrm{UV}_{\phi}} /(\text { p.f.u. })_{0_{\phi}}\right]_{\text {on irradiated host }}}{\left.[\text { (p.f.u. })_{\mathrm{UV}_{\phi}} /(\text { p.f.u. })_{0_{\phi}}\right]_{\text {on unirradiated host }}}$

where (p.f.u.) $)_{\mathrm{Uv}_{0}}$ is the titre of irradiated phages and (p.f.u. $)_{0_{0}}$ is the titre of the unirradiated lysate (Simonson et al., 1990).

Weigle mutagenesis of phages was determined using cell-free lysates of wild-type D3. Irradiation of host cells and phage infections were performed as described for Weigle reactivation experiments. After overnight incubation at $37^{\circ} \mathrm{C}$ in the dark, the frequency of clear-plaque mutants among the total plaques produced was determined.

\section{RESULTS}

\section{UV survival of plasmid-containing $P$. aeruginosa}

Plasmids were introduced into $P$. aeruginosa and their UV survival compared to isogenic strains lacking the plasmid (Fig. 1). Plasmid R2 (IncP-9) and the IncN plasmids, R46 and pKM101, were transferrable to $P$. aeruginosa and clearly resulted in increased UV resistance (Fig. 1a). While the IncP-1 plasmids, RP4 and R68.45 (Fig. 1b), were transferrable to $P$. aeruginosa, their presence did not confer enhanced UV resistance. Thus, it appeared that the $U V^{r}$ phenotype of pKM101 was stable and expressed in a $P$. aeruginosa background, while the species-specific UVresistance character of the IncP-1 UV-resistance plasmids was not supported by the $P$. aeruginosa genetic and physiological background.

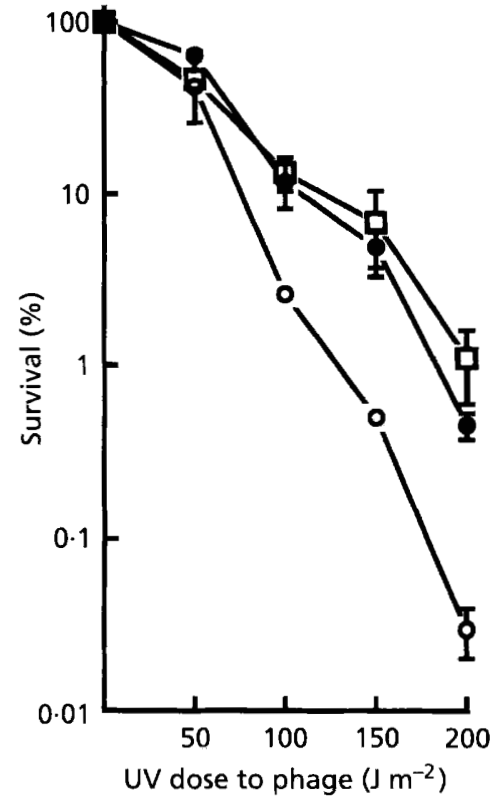

Fig. 2. Host-cell reactivation (HCR) of plasmid-containing $P$. aeruginosa. HCR was carried out as described in Methods, and strains with and without plasmids were compared. Lysates of phage D3c were irradiated with various doses of UV radiation and infected into host bacteria grown to the early exponential phase. Titres of irradiated phages were compared to unirradiated lysates in the same host. Means and standard errors are presented. P. aeruginosa PAO25 (O), PAO25(R2) (O), PAO25(pKM101) ( $\square$ ).

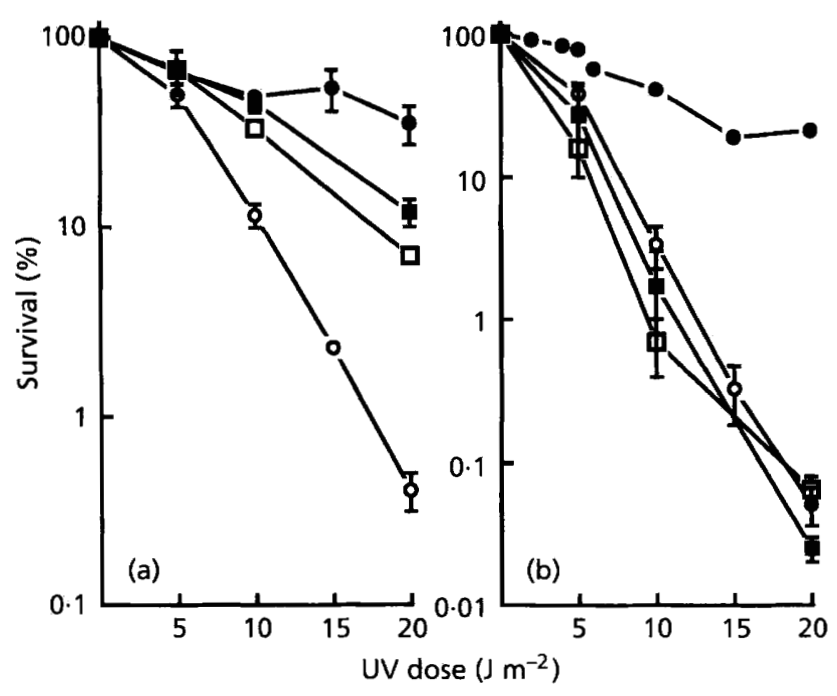

Fig. 1. UV survival of plasmid-containing $P$. aeruginosa. Plasmids were introduced into $P$. aeruginosa PAO strains, and their UV survival was compared with the parental strain that did not contain the plasmid. Cultures were grown to early exponential phase and exposed to various doses of UV radiation. The frequency of surviving cells was determined by plating on LB agar. Means and standard errors are presented. (a) P. aeruginosa PAO25 (O), PAO25(R2) (O), PAO25(R46) ( $\square$ ), PAO25(pKM101) (回. (b) PAO303 (O), PAO303(R2) (O), PAO303(RP4) ( $\square$ ), PAO303(R68.45) (匚). 


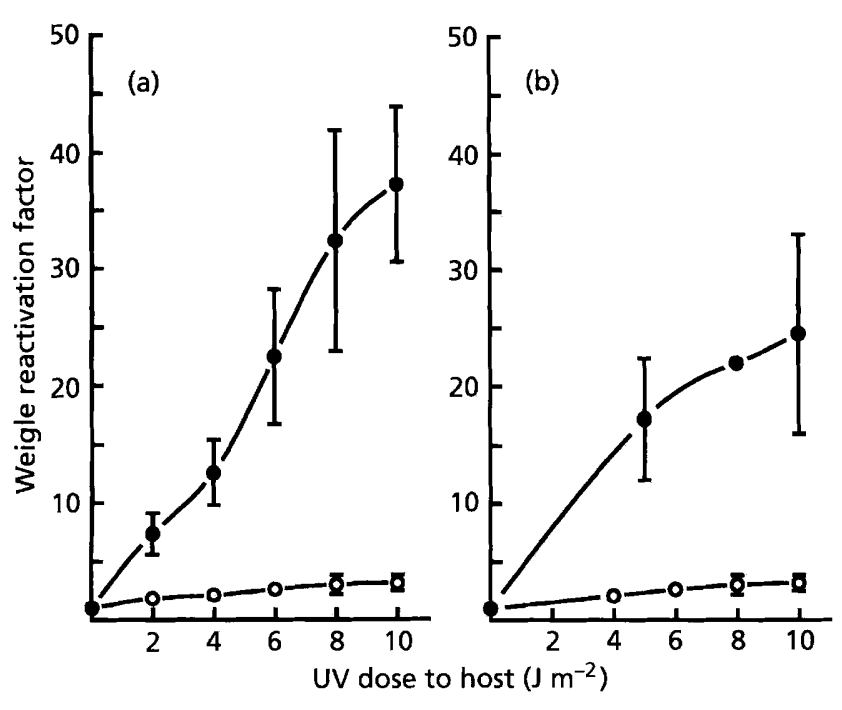

Fig. 3. Plasmid-stimulated Weigle reactivation of $P$. aeruginosa PAO25. Irradiated and unirradiated bacteriophages were used to infect host bacteria which had been exposed to various low doses of UV radiation. The Weigle reactivation factor (WRF) was calculated from the formula given in Methods and is a measure of the inducible DNA repair capacity of the host cell. Means and standard errors are presented. (a) PAO25 (O), PAO25(R2) (O). (b) PAO25 (O), PAO25(pKM101) (O).
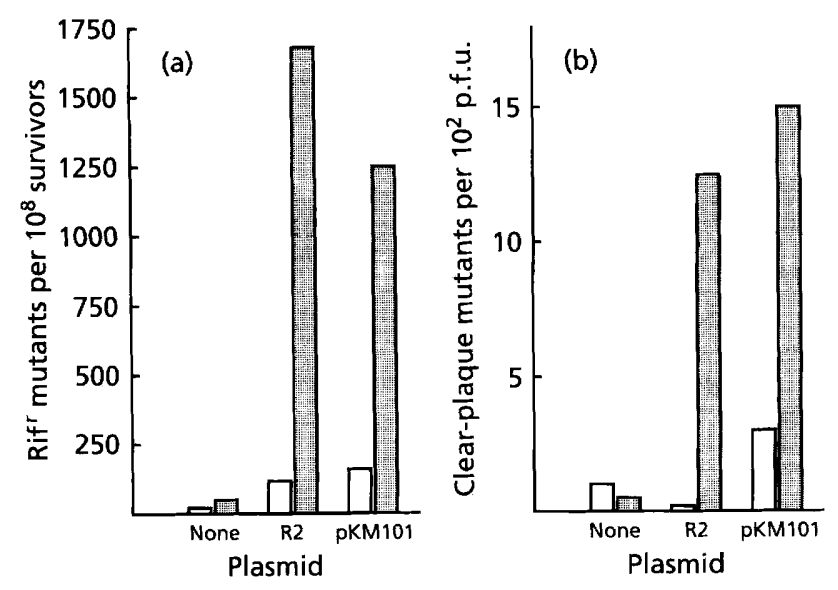

Fig. 4. UV-enhanced mutagenesis of $P$. aeruginosa. Spontaneous ( $\square$ ) and induced (圆) levels of mutagenesis associated with DNA-damage repair were compared for strains of PAO25 with and without various plasmids. (a) Induced levels of chromosomal mutation at $50 \%$ survival are compared to levels in cell populations that were not exposed to UV radiation. (b) Weigle mutagenesis frequencies of UV-irradiated wild-type D3 phages infected into unirradiated hosts (spontaneous) are compared to rates in hosts exposed to a dose of $3 \mathrm{~J} \mathrm{~m}^{-2}$ (induced).

\section{Host cell reactivation (HCR)}

UV resistance measured by kill curves potentially includes constitutively expressed and damage-inducible components. To assess if enhanced UV resistance encoded by plasmids in the IncP-9 and IncN incompatibility groups includes a constitutive component, a cell-free lysate of bacteriophage D3c was irradiated with various doses of UV radiation and the ability of cells with and without the plasmids R2 and pKM101 to repair the damage done to the phage genome was evaluated (Fig. 2). Both plasmids increased the host cell's capacity to repair DNA damage in the UV-irradiated phages. These data may indicate that the introduction of damaged phage DNA into the $P$. aeruginosa host cell acts to partially induce the UV-resistance gene of these plasmids, as has been observed in E. coli (Sedgwick, 1986; Ossanna et al., 1987). Alternatively, the increase in HCR when these plasmids are introduced into $\operatorname{Rec} A^{+} P$. aeruginosa may indicate that at least a fraction of the plasmid-encoded UV resistance potential is expressed constitutively in $P$. aeruginosa. McNally et al. (1990) have shown that a change of as little as one base pair in the SOS (LexA-binding) Box present in the $m u c A B$ genes of pKM101 allows some constitutive expression of these genes in E. coli. Any difference in the binding sequence required for binding of the presumptive $P$. aeruginosa LexA analogue protein could lead to low levels of expression of these plasmid-encoded UVresistance genes even in the absence of UV exposure.

\section{Plasmid-stimulated Weigle reactivation}

The inducible nature of plasmid-augmented UV resistance was investigated by quantifying the potential of cells with and without plasmids to carry out Weigle reactivation of UV-damaged bacteriophages. If DNA-damage-inducible repair is operative, a net increase in the production of plaques resulting from infection of UV-irradiated host cells is expected. The presence of IncP-9 or IncN plasmids significantly increases the level of Weigle reactivation and is clearly DNA-damage-inducible (Fig. 3). P. aeruginosa PAO expresses only a marginal level of repair in the absence of plasmids.

\section{Induction of mutagenesis by plasmid-encoded repair systems}

The ability of plasmids to stimulate chromosomal mutagenesis was quantified by determining the frequency of rifampicin-resistant cells in populations of $P$. aeruginosa. The presence of IncP-9 or IncN plasmids significantly increased the ability of cells to support DNA-damageinducible mutagenesis (Fig. 4a). Very little stimulation of mutagenesis was observed in cells that did not contain a plasmid. Spontaneous mutagenesis levels were also increased approximately tenfold in the presence of either plasmid. The spontaneous mutation frequency of $P$. aeruginosa PAO25 to Rif $^{r}$ was $1.7 \times 10^{-7}$. This frequency was increased to $1 \cdot 2 \times 10^{-6}$ when R2 (IncP-9) was present in the cell and to $1.6 \times 10^{-6}$ when pKM101 was present.

The frequency of clear-plaque mutants present among total plaques resulting from infection of cells with UVdamaged phages was determined by carrying out Weigle mutagenesis experiments (Fig. 4b). This analysis clearly demonstrates that IncP-9 and IncN plasmids resident in $P$. aeruginosa support inducible DNA repair and mutagenesis. 


\section{DISCUSSION}

Taken together, our experiments clearly indicate that plasmids pKM101 and R46 can be mobilized into $P$. aeruginosa $\mathrm{PAO}$, that they can replicate in this species and that these plasmids are capable of mediating DNAdamage-inducible UV resistance and mutagenesis activities in $P$. aeruginosa. However, the conjugal transfer of pKM101 from $E$. coli to $P$. aeruginosa $\mathrm{PAO}$ is inefficient. While some IncN plasmids or portions of IncN plasmids have been observed to integrate into the $P$. aeruginosa chromosome (Tardif \& Grant, 1982), it appears that replication of pKM101 was autonomous. Agarose gel electrophoretic analysis of plasmid DNA prepared from our $P$. aeruginosa transformants revealed the presence of plasmid DNA molecules of the same molecular size as pKM101. When this DNA was used to transform E. coli, the $\mathrm{UV}^{\mathrm{r}}$ phenotype was expressed and plasmid DNA could be isolated from the E. coli transformants (data not shown).

Our experiments suggest that control elements such as analogues of E. coli LexA and RecA proteins may be functioning in the induction of the UV-resistance and mutagenesis phenotype following exposure of plasmidcontaining cells to UV radiation. Garriga et al. (1992) have recently identified a potential lex. $A$ analogue in $P$. aeruginosa which has significant similarity to the lex $A$ gene of $E$. coli and several other Gram-negative species. In addition, the $P$. aeruginosa $\operatorname{rec} A$ gene contains a LexAbinding SOS consensus sequence (Sano \& Kageyama, 1987 ), and the $P$. aeruginosa RecA protein has been shown to regulate E. coli din-gene expression (Kokjohn \& Miller, 1987). Expression of the R46 and pKM101 muc $A B$ genes is regulated by Lex $A$ in $E$. coli and the regulatory sequence of these genes contains an SOS Box to which LexA protein has been shown to bind (McNally et al., 1990). Thus, regulation of muc $A B$ in $P$. aeruginosa is likely to be via RecA-LexA antagonism.

However, alternative explanations for the regulation of IncN plasmid-encoded enhancement of UV resistance in $P$. aeruginosa should be considered. For instance, it is possible that the muc $A B$ genes are expressed at low, but constitutive levels and that $P$. aeruginosa-specific, UVinducible gene products act to enhance their action following UV exposure. This explanation would be consistent with the HCR results we obtained in this study. Additionally, Sano \& Kageyama (1993) recently sequenced the $P$. aeruginosa UV-inducible pyocin AP41 gene and could not identify an SOS Box in the sequence. They also found that, when the gene was introduced into E. coli, production of pyocin AP41 was not inducible by exposure to UV radiation. Our research group has made similar observations following introduction of $P$. aeruginosa dingene promoters (Warner-Bartnicki \& Miller, 1992) into E. coli (A. L. Warner-Bartnicki \& R. V. Miller, unpublished). Thus, proteins other than LexA may be required for full induction of SOS gene expression in $P$. aeruginosa.

Final resolution of the question of regulation of the muc $A B$ operon in $P$. aeruginosa must await the isolation of a $P$. aeruginosa lex $A(\mathrm{def})$ mutation which does not produce functional LexA repressor. Use of a mutant containing such a mutation will allow measurement and comparison to wild-type cells of muc $A B$-specific mRNA and protein synthesis in an environment in which their expression should be unequivocally constitutive.

The data obtained in this study demonstrate that the IncP1 plasmids RP4 and R68.45 fail to express UV ${ }^{\mathrm{r}}$ phenotypes in $P$. aeruginosa. Experiments by other investigators have revealed the ability of these plasmids to express UVinducible repair and mutagenesis phenotypes in some species of bacteria (McCann \& Clarke, 1981; Hofemeister et al., 1979; Tardif \& Grant, 1983). The reason for species-specific expression of UV repair phenotypes is not clear and is under investigation.

The dynamics and ecology of UV-resistance plasmids in natural populations of bacteria are virtually unknown at present. The exact contribution to cell survival conferred by either plasmid-borne or chromosomal mutagenesis genes is unclear. However, it is now certain that the presence of analogues of $u m u D C$ is not universally found in the eubacteria. Experiments with Enterobacteriaceae have revealed that $u m u D C$ is not conserved even within a single genus (Sedgwick \& Goodwin, 1985). Other investigations with Pseudomonas spp. likewise reveal variability in the presence of chromosomally encoded, functional analogues of the $E$. coli umuDC genes in this genus (McBeth, 1989; Simonson et al., 1990).

Comprehension of the ecology of UV-resistance plasmids is further complicated by consideration of the effects of solar UV radiation on bacteria. Solar UV radiation consists of the UV portion of the spectrum not filtered out by the ozone layer of Earth, $290 \mathrm{~nm}$ and longer wavelengths (Jagger, 1985), but little is known concerning the ability of these wavelengths to induce SOS functions in microbes native to natural environments and their UVresistance plasmids. Surprisingly, expression of the UVinducible genes of pKM101 is effectively blocked by solar UV irradiation (Eisenstark, 1989). However, UV-resistance plasmids are readily obtainable in natural aquatic ecosystems (Bale et al., 1988), thus surviving the test of selection.

Our current knowledge is insufficient to allow an estimation of the contribution of UV-resistance genes to plasmid and cell survival in natural ecosystems. We have observed that $\mathrm{UV}^{\mathrm{r}}$ markers are often found associated with plasmids which also confer resistance to one or more heavy metals or other toxic compounds. The environmentally significant functions of the systems we equate with UV resistance may be in the protection of the host from the toxic and mutagenic effects of the exposure to, or detoxification of, these elements and compounds. A fuller understanding of the molecular basis for UV resistance associated with these plasmids will provide insight into the ways in which bacteria have dealt with various kinds of DNA-damaging stress through their evolutionary and recent history. 


\section{ACKNOWLEDGEMENTS}

These studies were supported by cooperative agreements CR818233 and CR20060 with the Gulf Breeze Environmental Research Laboratory of the US Environmental Protection Agency to R. V.M. and by University of Nebraska Water Center and University of Nebraska Biotechnology Center grants to T.A.K.

\section{REFERENCES}

Bale, M. J., Fry, J. C. \& Day, M. J. (1988). Transfer and occurrence of large mercury resistance plasmids in river epilithon. Appl Environ Microbiol 54, 972-978.

Benbrook, D. M. \& Miller, R. V. (1986). Effects of norfloxacin on DNA metabolism in Pseudomonas aeruginosa. Antimicrab Agents Chemother 29, 1-6.

Boronin, A. M. (1992). Diversity and relationships of Pseudomonas plasmids. In Pseudomonas: Molecular Biology and Biotechnology, pp. 329-340. Edited by E. Galli, S. Silver \& B. Witholt. Washington, DC: American Society for Microbiology.

Calero, S., Garriga, X. \& Barbé, J. (1991). One-step cloning system for isolation of bacterial lex.A-like genes. J Bacteriol 173, 7345-7350.

Cavenagh, M. M. \& Miller, R. V. (1986). Specialized transduction of Pseudomonas aeruginosa PAO by bacteriophage D3. J Bacteriol 165, $448-452$.

Clark, A. J. \& Margulies, A. D. (1965). Isolation and characterization of recombination deficient mutants of Escherichia coli. Proc Natl Acad Sci US A 53, 451-459.

Eisenstark, A. (1989). Bacterial genes involved in response to nearultraviolet radiation. Adv Genet 26, 99-147.

Garriga, X., Calero, S. \& Barbé, J. (1992). Nucleotide sequence analysis and comparison of the lex $A$ genes from Salmonella typhimurium, Erwinia carotovora, Pseudomonas aeruginosa and Pseudomonas putida. Mol \& Gen Genet 236, 125-135.

Glazebrook, J. A., Grewal, K. K. \& Strike, P. (1986). Molecular analysis of the UV protection and nutation genes carried by the I incompatibility group plasmid TP110. J Bacteriol 168, 251-256.

Haas, D. \& Holloway, B. W. (1978). Chromosome mobilization by the R plasmid R68.45: a tool in Pseudomonas genetics. Mol \& Gen Genet 158, 229-237.

Hofemeister, J., Kohler, H. \& Filippov, V. D. (1979). DNA repair in Proteus mirabilis. IV. Plasmid (R46)-mediated recovery and UV mutagenesis. Mol \& Gen Genet 176, 265-273.

Horn, J. M. \& Ohman, D. E. (1988). Autogenous regulation and kinetics of induction of Pseudomonas aeruginosa rec $A$ transcription as analyzed with operon fusions. J Bacteriol 170, 4699-4705.

Jacoby, G. A. (1977). Classification of plasmids in Pseudomonas aeruginosa. In Microbiology 1977, pp. 119-126. Edited by D. Schlessinger. Washington, DC: American Society for Microbiology.

Jacoby, G. A. (1978). Classification and physical properties of Pseudomonas plasmids. In Microbiology 1978, pp. 221-224. Edited by D. Schlessinger. Washington, DC: American Society for Microbiology.

Jagger, J. (1985). Solar-UV Actions on Living Cells. New York: Praeger Publishing Co.

Kokjohn, T. A. \& Miller, R. V. (1987). Characterization of the Pseudomonas aeruginosa rec $A$ analog and its protein product: rec-102 is a mutant allele of the P. aeruginosa PAO rec A gene. J Bacteriol 169, 1499-1508.

McBeth, D. L. (1989). Effect of degradative plasmid CAM-OCT on responses of Pseudomonas bacteria to UV light. J Bacteriol 171, 975-982.
McCann, K. \& Clarke, C. H. (1981). Plasmid-mediated UV-protection in Myxococcus xantbus. Mol \& Gen Genet 182, 137--142.

McNally, K. O., Freitag, N. E. \& Walker, G. C. (1990). LexAindependent expression of a mutant muc $A B$ operon. J Bacteriol 172, 6223-6231.

Miller, R. V. \& Kokjohn, T. A. (1988). Expression of the $r e c A$ gene of Psezdomonas aeruginosa $\mathrm{PAO}$ is inducible by DNA-damaging agents. J Bacteriol 170, 2385-2387.

Miller, R. V. \& Kokjohn, T. A. (1990). General microbiology of $\operatorname{rec} A$ : environmental and evolutionary significance. Annu Rev Microbiol 44, 265-294.

Miller, R. V. \& Ku, C.-M. C. (1978). Characterization of Pseudomonas aeruginosa mutants deficient in the establishment of lysogeny. $J$ Bacteriol 134, 875-883.

Mortelmans, K. E. \& Stocker, B. A. D. (1976). Ultraviolet light protection, enhancement of ultraviolet light mutagenesis, and mutator effect of plasmid R46 in Salmonella typhimurium. J Bacteriol 128, 271-282.

Ossanna, N., Peterson, K. R. \& Mount, D. W. (1987). UV-inducible SOS response in Escherichia coli. Photochem Photobiol 45, 905-908.

Pinney, R. J. (1980). Distribution among incompatibility groups of plasmids that confer UV mutability and UV resistance. Mutat Res 72, 155-159.

Sano, Y. \& Kageyama, M. (1987). The sequence and function of the $r e c A$ gene and its protein in $P$ seudomonas aeruginosa $\mathrm{PAO}$. Mol \& Gen Genet 208, 412-419.

Sano, Y. \& Kageyama, M. (1993). A novel transposon-like structure carries the genes for pyocin AP41, a Pseudomonas aeruginosa bacteriocin with a DNase domain homology to E2 group colicins. Mol \& Gen Genet 237, 161-170.

Sedgwick, S. G. (1986). Inducible DNA repair in microbes. Microbiol Sci 3, 76-83.

Sedgwick, S. G. \& Goodwin, P. A. (1985). Differences in mutagenic and recombinational DNA repair in enterobacteria. Proc Natl Acad Sci USA 82, 4172-4176.

Sedgwick, S. G., Thomas, S. M., Hughes, V. M., Lodwick, D. \& Strike, P. (1989). Mutagenic DNA repair genes on plasmids from the pre-antibiotic era. Mol \& Gen Genet 218, 323-329.

Simonson, C. S., Kokjohn, T. A. \& Miller, R. V. (1990). Inducible UV repair potential of Pseudomonas aeruginosa PAO.J Gen Microbiol 136, 1241-1249.

Strike, P. \& Lodwick, D. (1987). Plasmid genes affecting DNA repair and mutation. J Cell Sci Suppl. 6, 303-321.

Tardif, G. \& Grant, R. B. (1982). Transfer of IncN plasmids to Pseudomonas aeruginosa. Antimicrob Agents Cbemother 22, 142-144.

Tardif, G. \& Grant, R. B. (1983). Transfer of plasmids from Escherichia coli to a Pseudomonas aeruginosa mutant with enhanced recipient ability for enterobacterial plasmids. Antimicrob Agents Chemother 24, 201-208.

Walker, G. C. (1977). Plasmid (pKM101)-mediated enhancement of repair and mutagenesis: dependence on chromosomal genes in Escherichia coli K-12. Mol \& Gen Genet 152, 93-103.

Walker, G. C. (1984). Mutagenesis and inducible responses to deoxyribonucleic acid damage in Eschericbia coli. Microbiol Rev 48, $60-93$.

Warner-Bartnicki, A. L. \& Miller, R. V. (1992). Characterization of stress-responsive behavior in Pseudomonas aeruginosa PAO: isolation of Tn3-lacZYA fusions with novel damage-inducible (din) promoters. J Bacteriol 174, 1962-1968.

Received 28 June 1993; revised 31 August 1993; accepted 10 September 1993. 